\section{Case Reports in Neurology}

Case Rep Neurol 2020;12:34-40

DOI: 10.1159/000507752

Published online: December 14, 2020
(C) 2020 The Author(s)

Published by S. Karger AG, Base www.karger.com/crn

This article is licensed under the Creative Commons Attribution-NonCommercial 4.0 International License (CC BY-NC) (http://www.karger.com/Services/OpenAccessLicense) Usage and distribution for commercial purposes requires written permission.

\title{
A Case of Successful Intravenous Thrombolysis Bridged with Repeated Endovascular Treatment in Acute Basilar Artery Occlusion
}

\author{
Binh Nguyen Pham ${ }^{\mathrm{a}}$ Hoang Thi Phan ${ }^{\mathrm{a}-\mathrm{c}}$ Trung Quoc Nguyen ${ }^{\mathrm{a}}$ \\ Thang Huy Nguyen ${ }^{a, b}$ \\ a115 People's Hospital, Ho Chi Minh City, Vietnam; bPham Ngoc Thach University of \\ Medicine, Ho Chi Minh City, Vietnam; 'Menzies Institute for Medical Research, University \\ of Tasmania, Hobart, TAS, Australia
}

\section{Keywords}

Acute basilar artery occlusion - Thrombectomy - Endovascular treatment .

Angioplasty/stenting in intracranial atherosclerosis $\cdot$ Recurrent stroke $\cdot$ Large vessel occlusion

\begin{abstract}
Acute basilar artery occlusion (BAO) is a neurological emergency that has a high rate of mortality and poor functional outcome. Endovascular therapy (ET) is the gold standard therapy for large vessel occlusion stroke of the anterior circulation. Whether ET can also be effectively and safely performed in early recurrent large vessel occlusion, especially in BAO, is unclear. We describe a case of successful recanalization and independent functional outcome of a BAO patient treated with intravenous thrombolysis combined with repeated ET. The patients was a 32-year-old man with a history of heavy smoking and drinking who presented to the Emergency Department with dizziness and hypertension, and progressed over the next $13 \mathrm{~h}$ to left hemiparesis and mild dysarthria with an NIHSS score of 7. CT angiography demonstrated occlusion of the proximal basilar artery (BA). Intravenous alteplase was given followed by ET. The first intervention failed and over the next $8 \mathrm{~h}$, the patient's NIHSS score increased to 12. A second attempt with balloon angioplasty managed to reconstitute arterial blood flow with a severe residual stenosis of the proximal BA. Subsequently, the patient progressed into deep
\end{abstract}

Thang Huy Nguyen
Cerebrovascular Disease Department
115 People's Hospital, 527 Su Van Hanh Street, District 10
Ho Chi Minh City, 70000 (Vietnam)
nguyenhuythang115@gmail.com




\section{Case Reports in Neurology}

Case Rep Neurol 2020;12:34-40

\begin{tabular}{l|l}
\hline DOI: 10.1159/000507752 & $\odot 2020$ The Author(s). Published by S. Karger AG, Basel \\
\hline
\end{tabular} www.karger.com/crn

Pham et al.: Bridging Therapy with Repeated Endovascular Treatment in Acute Basilar Occlusion

coma with reocclusion of the BA demonstrated on transcranial Doppler. A third intervention with emergent stenting resulted in complete recanalization of the BA and excellent neurological recovery. This patient received three endovascular treatments within $24 \mathrm{~h}$ due to reocclusion of the BA and achieved good outcomes. In conclusion, repeated ET for early recurrent $\mathrm{BAO}$ is feasible in carefully selected patients.

(c) 2020 The Author(s)

Published by S. Karger AG, Basel

\section{Introduction}

The posterior circulation is involved in about a fifth of all ischemic strokes. Blood supply to the posterior circulation depends on one main artery, the basilar artery (BA). The prognosis of acute basilar artery occlusion (BAO) is very poor, with $85-95 \%$ mortality if patency of the BA cannot be re-established [1, 2]. Endovascular therapy (ET) has been proven effective for the treatment of large vessel occlusion (LVO) strokes. However, the feasibility and potential benefits of repeated ET for recurrent LVO is unclear. There are only a few reports on repeated thrombectomies for LVO stroke, mostly in anterior circulation [3-5]. Here, we present a patient with recurrent stroke due to occlusion of the BA who was successfully treated by ET thrice within $24 \mathrm{~h}$.

\section{Case Presentation}

A 32-year-old man, with a history of heavy smoking and excessive drinking (more than 30 cigarettes a day and 30 drinks per week for nearly 14 years) and a 2-year history of poorly controlled hypertension, was brought to the emergency room with complaints of fatigue and dizziness which had started $4 \mathrm{~h}$ earlier. Physical examination and non-contrast computer tomography (CT) of the head on arrival were unremarkable except for a high blood pressure of 230/120 mm Hg. Nicardipine was administered to stabilize his blood pressure. After $9 \mathrm{~h}$, the patient developed left-sided weakness, severe vertigo, and vomiting while neurological examination revealed horizontal nystagmus in both eyes, mild dysarthria and ataxia with a National Institute of Health Stroke Scale (NIHSS) score of 7. He was promptly sent for CT angiography which revealed acute proximal BA thrombosis without obvious ischemic changes on non-contrast CT (Fig. 1a, b). The patient was diagnosed with acute BAO and received thrombolysis with intravenous alteplase and was transferred to the angiography suite for mechanical thrombectomy. However, the first intervention failed to restore the flow of BA (Fig. 1c), and the procedure was stopped after good collateral flow from anterior circulation was found. Over the next $8 \mathrm{~h}$, the patient deteriorated further with drowsiness and quadriparesis and his NIHSS score increased to 12. Magnetic resonance imaging (MRI) scan now showed a small pontine infarct. The patient was brought to the endovascular suite for a second time and dilation of the proximal BA was performed twice with a $2.5 \times 15 \mathrm{~mm}$ balloon. Although arterial flow was reconstituted, residual severe stenosis persisted in the proximal BA with impaired distal flow (Fig. 1d). The patient regained consciousness temporarily after the procedure. At 24-h post-thrombolysis, we administered a loading dose of aspirin and clopidogrel combined with a high dose of statin. Unfortunately, in the following morning, the patient became progressively debilitated with quadriplegia and bilateral Babinski sign, and his Glasgow Coma Scale (GCS) score was 6. Immediate CT of the brain and transcranial Doppler (TCD) excluded

\section{Karger'=}




\section{Case Reports in Neurology}

Case Rep Neurol 2020;12:34-40

\begin{tabular}{l|l}
\hline DOI: 10.1159/000507752 & ๑ 2020 The Author(s). Published by S. Karger AG, Basel
\end{tabular} www.karger.com/crn

Pham et al.: Bridging Therapy with Repeated Endovascular Treatment in Acute Basilar Occlusion

cerebral hemorrhage but confirmed reocclusion of the BA. After multidisciplinary discussion among neurologists and interventionists, we proceeded to immediate angioplasty and stenting of the BA. This time the vessel became fully patent with an excellent angiographic recanalization of TICI 3 (Fig. 1e). After the procedure, the patient was transferred to the intensive care unit and on the following day, he was conscious, spoke clearly with only mild weakness in the limbs and his NIHSS score decreased to 5. On review of repeat MRI and TCD, there was no progression of ischemic stroke or symptomatic intracerebral hemorrhage (Fig. 2), and his BA remained patent. The patient was discharged on the 7th day of hospitalization with dual antiplatelet therapy and a high dose of statin amongst other risk factor control measures.

\section{Discussion}

BAO is a relatively infrequent but devastating condition which can lead to severe neurological deficits. The most common clinical manifestations of BAO are a reduced level of consciousness, hemiparesis or quadriparesis, gaze abnormalities, and cranial nerve palsies. Disruption in the BA's blood supply to the reticular activating system can result in catastrophic locked-in syndrome with quadriplegia and anarthria. Occlusion of a major artery, such as the $\mathrm{BA}$, is challenging to treat because of suboptimal response to thrombolysis with intravenous tPA and high rates of reocclusion following successful initial recanalization, especially in the presence of underlying intracranial atherosclerotic disease (ICAD) prevalent in Asian stroke patients. In this situation, repeated ET with balloon angioplasty and stenting can be considered as rescue therapy. Without early recanalization, the prognosis of acute BAO is usually very poor. As the collateral circulation of the posterior circulation was more abundant compared to anterior circulation, it has been argued that the thrombolysis time window can potentially be prolonged in posterior circulation stroke [5]. Several studies suggested that recanalization therapies for BAO can potentially benefit patients up to 12-24 $\mathrm{h}$ after symptom onset [6-8]. As a result, our center has adopted a thrombolysis time window up to $24 \mathrm{~h}$ in BAO and posterior circulation infarcts without evidence of large ischemic lesions on neuroimaging. In our patient, intravenous alteplase was administered $14 \mathrm{~h}$ after onset of his first symptoms that was immediately bridged with endovascular treatment. The guidewire could not pass through the occlusion and we failed to achieve recanalization at the first intervention. During the procedure, good collateral flow from the anterior circulation was shown, which could explain the slow progression of neurological symptoms. During the second attempt, balloon angioplasty resulted in partial recanalization of the BA, and aggressive medical management as recommended in the SAMMPRIS trial was initiated $24 \mathrm{~h}$ post-thrombolysis [9]. We tried to avoid emergency stenting, as antithrombotic therapy given within $24 \mathrm{~h}$ of alteplase treatment could increase the risk of intracranial hemorrhage, and this procedure was previously reported to increase the risk of hemorrhage and reocclusion $[10,11]$. The patient further deteriorated to a comatose state due to BA reocclusion. Angioplasty and stenting in the third attempt resulted in complete recanalization (TICI 3) of the BA accompanied with excellent neurological recovery. Our patient with acute posterior circulation infarction and underlying ICAD underwent ET of the same occluded BA thrice within $24 \mathrm{~h}$. Data on repeated ET for early recurrent stroke caused by the occlusion of the same affected vessel are scarce. To our knowledge, there are only a few case reports $[3-5,12]$ and two retrospective studies with repeated ET due to recurrent LVO $[13,14]$, but mostly in the anterior circulation. Our case report is the first on repeated ET within the BA. Repeated ET may lead to more severe

\section{Karger'=}




\section{Case Reports in Neurology}

Case Rep Neurol 2020;12:34-40 DOI: 10.1159/000507752

(c) 2020 The Author(s). Published by S. Karger AG, Basel www.karger.com/crn

Pham et al.: Bridging Therapy with Repeated Endovascular Treatment in Acute Basilar Occlusion

disruption of the vascular endothelium, thereby increasing the risk of complications such as vasospasm, arterial dissection, as well as perforation [15]. However, no intraprocedural complication was recorded in our patient. Evidence on the safety and effectiveness of repeated thrombectomy in elderly patients compared with younger patients is unclear due to limited data. Our case demonstrates that even repeated ET can be technically feasible and safe and may result in remarkable clinical improvement in BAO.

The most common causes of $\mathrm{BAO}$ are atherosclerotic disease resulting from local thrombosis due to severe stenosis and thromboembolism from cardiac and large artery sources. The mechanism differs depending on the affected segment. Lodging of an embolic source is much more frequent in the distal third of the BA, especially at the top of the BA. Atherosclerosis often involves both vertebral arteries and leads mostly to occlusion of the proximal and middle segments of the BA, which is presented in this case. Rare causes of BAO, including vascular dissection, vasospastic syndrome had no evidence on DSA imaging. Other follow-up test results included high LDL-c lipid profile, nonsignificant carotid artery stenosis, sinus rhythm on the $24 \mathrm{~h}$ electrocardiogram, negative PFO under TCD, and normal cardiac ultrasound, which confirmed the intracranial atherosclerosis cause of the vascular occlusion.

In conclusion, repeated ET for early recurrent LVO stroke, especially in acute BAO appears feasible in carefully selected patients. A previous thrombectomy should not discourage repeated aggressive treatment as these patients may achieve similar rates of good clinical outcome as those who undergo single thrombectomy. In addition, angioplasty with stenting could be considered in the primary treatment in future cases with underlying ICAD to prevent reocclusion.

\section{Acknowledgements}

Dr. Vu Thanh Tran, Dr. Tri Quang Nguyen, and Dr. Chau Quynh Thi Bui interpreted the images, treated the patient, and provided patient data.

\section{Statement of Ethics}

Written informed consent was obtained from the patient for publication of this case report and any accompanying images.

\section{Disclosure Statement}

The authors have no conflicts of interest to declare.

\section{Funding Sources}

The authors received no financial support for the research, authorship, and publication of this article.

\section{Karger'"}




\section{Case Reports in Neurology}

\section{Author Contributions}

Binh N. Pham was a major contributor in performing the literature review, analyzing data, and writing the manuscript. Thang H. Nguyen interpreted the patient data and was a major contributor to the conception of the work and drafting the manuscript. Hoang T. Phan and Trung Q. Nguyen contributed to interpretation of data for the work and made substantial contributions to drafting and revising the manuscript critically for important intellectual content. All authors read and approved the final manuscript.

\section{References}

1 Hacke W, Zeumer H, Ferbert A, Brückmann H, del Zoppo GJ. Intra-arterial thrombolytic therapy improves outcome in patients with acute vertebrobasilar occlusive disease. Stroke. 1988 Oct;19(10):1216-22.

2 Brandt T, von Kummer R, Müller-Küppers M, Hacke W. Thrombolytic therapy of acute basilar artery occlusion. Variables affecting recanalization and outcome. Stroke. 1996 May;27(5):875-81.

3 Lee Y, Yi H, Kim BM, Kim DJ, Kim SH, Nam HS, et al. Recurrent Cardioembolic Stroke Treated Successfully with Repeated Mechanical Thrombectomy within the Acute Index Stroke Period. J Clin Neurol. 2015 Jul;11(3):275-8.

4 Laible M, Möhlenbruch M, Hacke W, Bendszus M, Ringleb PA, Rizos T. Repeated Intra-Arterial Thrombectomy within 72 Hours in a Patient with a Clear Contraindication for Intravenous Thrombolysis. Case Rep Vasc Med. 2015;2015:872817.

5 Tejada Meza H, Barrena Caballo MR, Guelbenzu Morte S, Martínez García R, Marta Moreno J. Repeated mechanical thrombectomy in the same intracranial artery segment. J Stroke Cerebrovasc Dis. 2017 Sep;26(9):e180-2.

6 Lindsberg PJ, Mattle HP. Therapy of basilar artery occlusion: a systematic analysis comparing intra-arterial and intravenous thrombolysis. Stroke. 2006 Mar;37(3):922-8.

7 Mattle HP, Arnold M, Lindsberg PJ, Schonewille WJ, Schroth G. Basilar artery occlusion. Lancet Neurol. 2011 Nov;10(11):1002-14.

8 Lindsberg PJ, Soinne L, Tatlisumak T, Roine RO, Kallela M, Häppölä O, et al. Long-term outcome after intravenous thrombolysis of basilar artery occlusion. JAMA. 2004 Oct;292(15):1862-6.

9 Chimowitz MI, Lynn MJ, Derdeyn CP, Turan TN, Fiorella D, Lane BF, et al; SAMMPRIS Trial Investigators. Stenting versus aggressive medical therapy for intracranial arterial stenosis. N Engl J Med. 2011 Sep;365(11):993-1003.

10 Shi M, Wang S, Zhu H, Feng J, Wu J. Emergent stent placement following intra-arterial thrombolysis for the treatment of acute basilar artery occlusion. J Clin Neurosci. 2012 Jan;19(1):152-4.

11 Levy EI, Hanel RA, Boulos AS, Bendok BR, Kim SH, Gibbons KJ, et al. Comparison of periprocedure complications resulting from direct stent placement compared with those due to conventional and staged stent placement in the basilar artery. J Neurosurg. 2003 Oct;99(4):653-60.

12 Fandler S, Deutschmann H, Fazekas F, Gattringer T. Repeated endovascular treatment of early recurrent proximal middle cerebral artery occlusion: case report and brief review of the literature. Front Neurol. 2018 May;9:289.

13 Bouslama M, Haussen DC, Rebello LC, Grossberg JA, Frankel MR, Nogueira RG. Repeated mechanical thrombectomy in recurrent large vessel occlusion acute ischemic stroke. Intervent Neurol. 2017 Mar;6(12):1-7.

14 Bhogal P, AlMatter M, Hellstern V, Pérez MA, Ganslandt O, Bäzner H, et al. Mechanical thrombectomy for recurrent large vessel occlusion. J Clin Neurosci. 2019 Aug;66:107-12.

15 Behme D, Gondecki L, Fiethen S, Kowoll A, Mpotsaris A, Weber W. Complications of mechanical thrombectomy for acute ischemic stroke-a retrospective single-center study of 176 consecutive cases. Neuroradiology. 2014 Jun;56(6):467-76. 


\section{Case Reports in Neurology}
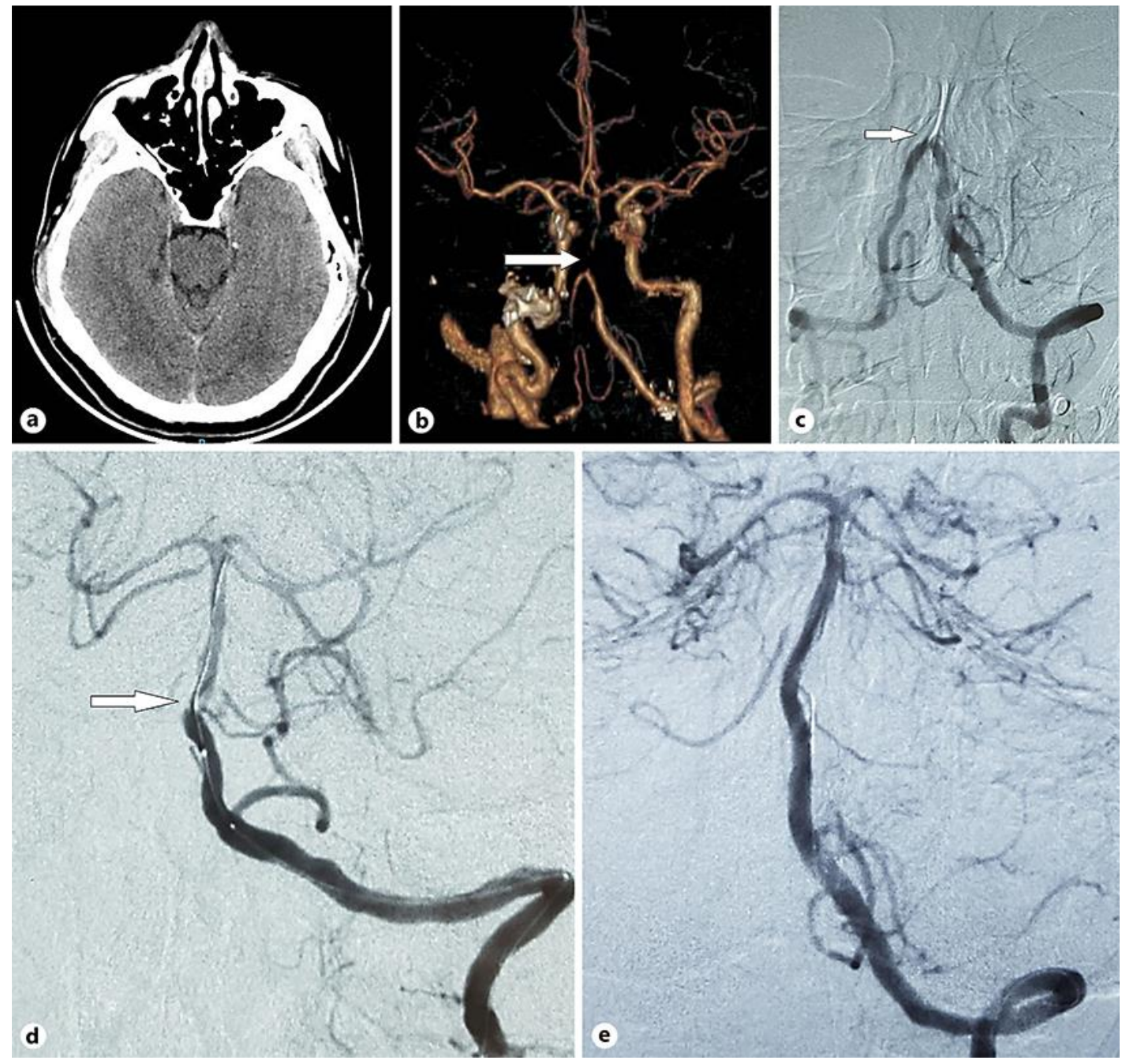

Fig. 1. Angiography of BA. a Non-contrast CT with no hemorrhage. b CTA: occlusion of the proximal BA (arrow). c BAO, failure to recanalize at first attempt. d BA severe atherosclerotic stenosis after balloon dilatation. e Stent angioplasty with angiographic result of TICI 3. 
Case Reports in Neurology

\begin{tabular}{l|l}
\hline Case Rep Neurol 2020;12:34-40 \\
\hline DOI: 10.1159/000507752 & $\begin{array}{l}\text { @ 2020 The Author(s). Published by S. Karger AG, Basel } \\
\text { www.karger.com/crn }\end{array}$ \\
\hline
\end{tabular}

Pham et al.: Bridging Therapy with Repeated Endovascular Treatment in Acute Basilar Occlusion
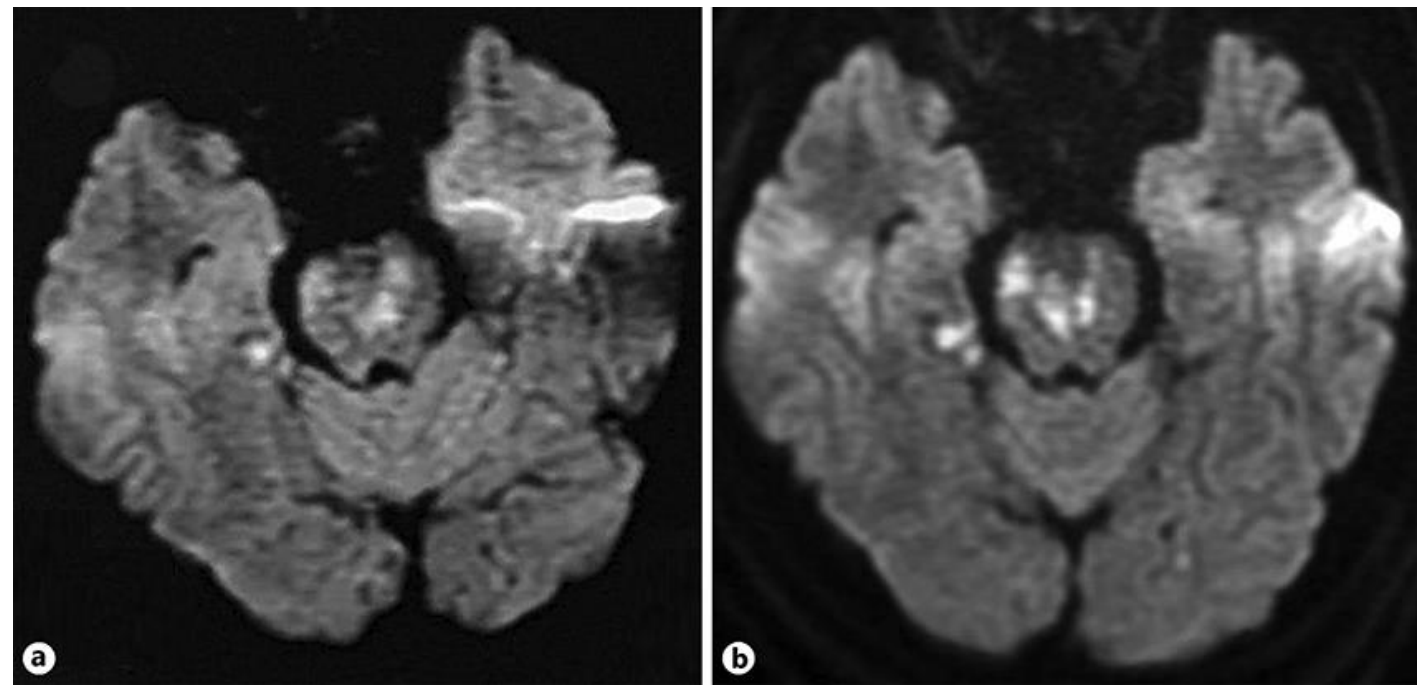

Fig. 2. Diffusion-weighted magnetic resonance image showing punctate diffusion bright lesions in the pons. a Initial MRI scan after the first thrombectomy showing small DWI lesions. b Last MRI scan after successful recanalization showing little progression in ischemic stroke. 